\title{
Family Cohesion and School Belonging in Pre- adolescence: Examining the Mediating Role of Security and Achievement Goals
}

\author{
Yuhui Qin ${ }^{1}$, Xiang Wan ${ }^{1}$, Shishuo $\mathrm{Qu}^{2}$, and Gong Chen ${ }^{1}$ \\ ${ }^{1}$ Department of Psychology, Wuhan University, 430072 Wuhan Hubei, China \\ ${ }^{2}$ Department of Sociology, Wuhan University, 430072 Wuhan Hubei, China
}

\begin{abstract}
There have been plenty of researches about how to improve a sense of school belonging. However, few of the studies start from the cooperation of family and school. This study utilizes a sample of 365 students aged from 7 years old to 20 years old to reveal the relationships of family cohesion and school belonging. The mediating effects of security and achievement goals are also examined. The correlational results indicate that family cohesion is positively and significantly associated with school belonging, interpersonal security and mastery goals. School belonging links to interpersonal security, mastery goals, performance-approach goals and performance-avoidance goals positively and prominently. The structural model manifests that family cohesion can predict school belonging not only positively and directly but also via the mediating role of interpersonal security and achievement goals, which only includes mastery-oriented goals, namely mastery goals and performance-approach goals. This research suggests that the cooperation of family and school is effective and emphasizes the importance of mental wellbeing as the mediator.
\end{abstract}

Keyword. family cohesion; school belonging; interpersonal security; achievement goals

\section{Introduction}

Researches have shown that children with distressed fathers will experience less positive fathering and more family conflicts, which might influence their mental health (Yoo, Adamsons, Robinson, \& Sabatelli, 2015). If Parents do not handle the acculturation differences with children or do not engage in children's education, adolescents will reflect less family cohesion and endure more developmental risks. Children who come from divorced family might experience less self-efficacy, educational wellbeing and a sense of security (Bowlby, 1982;Crespo, Kielpikowski, Pryor, \& Jose, 2011; Leidy, Guerra, \& Toro, 2012). Instead, children from cohesive family believe in their capacity to fulfill their goals more firmly, perceive more interpersonal support and have higher self-esteem as well as a 
sense of security (Bowlby, 2008; Merkaš \& Brajša-Žganec, 2011). Adolescents from cohesive family reflect more life satisfaction, positive effects and social inclusion while those from divorced family show more aggression and hostility (Hamama \& Arazi, 2012; Moreira, Frontini, Bullinger, \& Canavarro, 2014). Apparently, family, especially family cohesion, plays an important role in adolescents' wellbeing and adaptation. Some researches indicate that if parents can join hands with school, there will be a better climate for children's development (Cheung, 2011; Yuhui \& Xiang, 2015).

\section{Family cohesion and school belonging}

Family cohesion can be defined as the emotional bonding in family members and it represents the level of unity and togetherness within family (Olson et al., 1982). Family cohesion also stands for support, care and emotional closeness among family members (Tolan, Gorman-Smith, Huesmann, \& Zelli, 1997). As for school belonging, it's initially viewed as the perception of being received, respected and supported in the school settings (Goodenow, 1993). Then researchers emphasize the role of peers and teachers in school climate (Hagborg, 1994). Gradually, school belonging can be partitioned into three aspects: the school contexts in which students feel accepted and supported; the positive relationships with peers and faculties and the identification with school values, facilities and schoolbased activities (Faircloth \& Hamm, 2005).

Parental warmth and positive involvement predict children's adaptation in school climate. Positive relationships with peers and teachers predict high school belonging while conflicts with classmates and faculties bring down school belonging (Leidy et al., 2012; Maurizi, Ceballo, Epstein-Ngo, \& Cortina, 2013). In cohesive family, parents will be more engaged in children's education. They will keep a close eye on children and guide them how to think, to interact with friends and to deal with other social problems. And they will restrict children from misconduct. Through this process, Children acquire social skills, become well received among peers, and develop strong school belonging (Sijtsema et al., 2013). On the contrary, since students from divorced family are less supervised by parents, they are more prone to aggression, hostility and problem behaviors, which will make them less popular among peers and identified with school (Hamama \& Arazi, 2012). Besides, according to the participation-identification theory, the success of participation in school activities links to identification with school climate, of which school belonging is one of the most important parts (Wehlage, 1989). Students from cohesive family show more prosocial behavior and better social inclusion (Moreira et al., 2014). They may get more involved in school-based activities and develop strong school belonging.

\section{The mediating role of security}

A sense of security is one of the basic human needs (Maslow, Hirsh, Stein, \& Honigmann, 1945). It indicates individual's perception whether they are subject to possible harm and are able to solve the problems. There are two types of securities, the interpersonal security and the control security. Interpersonal security indicates the degree to which individuals feel secure in interpersonal relationship. Control security is individuals' perception that they can take control of their lives (Cong, 2004). Interpersonal security is one of the most important aspects in a sense of security. Children with low interpersonal security may have trouble in interpersonal relationships. They may be prone to anxiety and be uncomfortable in interacting with others (Liao, Hu, \& Zhang, 2014).

Parenting proves to be a direct factor of the sense of security. A lack of parental communication and attachment can negatively affect children's sense of security and bring 
about threat and anxiety (Bowlby, 2008; Liao et al., 2014; Lindahl \& Malik, 2011). Only in a supportive and cohesive family context can children establish a stable sense of security (Bowlby, 1982).

Individuals who have a strong sense of security might acquire more support, care and acceptance. They may be optimistic and may develop a feeling of belonging. Instead, those who are devoid of a sense of security may be more likely to feel rejected, lonely and frustrated, which may lead to a weak sense of belonging (Maslow et al., 1945). And a sense of security is conducive to relationship satisfaction (Mikulincer, Shaver, \& Rom, 2011), which may contribute to positive relationships with classmates and teachers and thus increase school belonging (Maurizi et al., 2013).

\section{The mediating role of achievement goals}

Initially, achievement goals can be partitioned into two classes; learning goals and performance goals. Then achievement goal theorists integrated the approach-avoidance motivation and put forward three types of goals: mastery goals, performance-approach goals and performance-avoidance goals. Individuals with learning goals pursue enhancing competence, gaining new knowledge and handling the challenges (mastery goals) while those with performance goals quest for positive evaluation of competence (performanceapproach goals) and avoid negative judgement of their capacity (performance-avoidance goals) (Dweck \& Bempechat, 1983). Compared with mastery goals and performanceapproach goals, performance-avoidance goals in essence lead to a decrease in intrinsic motivation. Therefore, the adverse effects of achievement goals work only on performanceavoidance goals (Elliot \& Harackiewicz, 1996).

If individuals believe in their competence, they may go after challenges and persist in their tasks, which contribute to mastery goals and performance-approach goals. If individuals are not confident in their capacity, they may avoid challenges and hold back, which leads to performance-avoidance goals (Dweck, 1986). Positive parenting and family communication are linked to children's social and academic self-efficacy (Asghari, Saadat, Atefi Karajvandani, \& Janalizadeh Kokaneh, 2014; Leidy et al., 2012). Students from cohesive family may thus have more faith in their competence and are more inclined to hold mastery-oriented goals, namely mastery goals and performance-approach goals.

According to the identify-instruction integration theory (Faircloth \& Hamm, 2005), if students have positive feedbacks in school, they are more likely to identify with school and develop school belonging. And teachers' guidance and better academic performance will also contribute to school belonging (Cook, Purdie-Vaughns, Garcia, \& Cohen, 2012). Students who have mastery goals and performance-approach goals will go after challenges and adhere to their assignments when facing academic problems. They are more inclined to have better academic performance and receive more positive feedbacks from teachers than those who hold performance-avoidance goals, which may enhance their school belonging.

\section{Present studies}

Some researchers suggest that the study of school belonging should emphasize the cooperation of family and school (Cheung, 2011). Recent studies have suggested that family cohesion is positively associated with parental conditions and children's wellbeing, competence and attachment (Hamama \& Arazi, 2012; Leidy et al., 2012; Liao et al., 2014). However, few researches probe into the relationship of family cohesion and school belonging and the mediating role of security and achievement goals in the process. This study examines three hypotheses. First, family is positively associated with school 
belonging. Second, security, especially the interpersonal security plays a mediating role in the relationship of family cohesion and school belonging. Family cohesion is positively correlated to interpersonal security. Interpersonal security is conducive to school belonging. What's more, family cohesion positively predicts school belonging via interpersonal security. Third, family cohesion links to achievement goals, especially mastery goals and performance-approach goals positively. Mastery goals and performance-approach goals positively correlate to school belonging. Family cohesion positively predict school belonging through mastery-oriented goals, namely mastery goals and performanceapproach goals. Through this study, we expect to find out the influence of family variables on students' school belonging, which is conducive to the family-school support programs of students.

\section{Method}

\section{Participants}

Four hundred and eleven participants (225 boys; 182 girls; $M$ age $=11.52 ; S D=2.08$ ) were recruited from five schools in China. Forty-six participants were excluded from analyses since they failed a red herring question which was intended to spot false responses. Therefore, only a sample of three hundred and sixty-five participants entered analyses (197 boys; 168 girls; $M$ age $=11.68 ; S D=2.06$ ). And students were rewarded with a small gift after they finished the questionnaire on paper.

\section{Procedures and data analyses}

The research started in voluntary teaching. There are three ways to collect data. First, the voluntary teachers made home visits. If the parents approved of the study, they would guide students in finishing the questionnaires on paper. Second, the voluntary teachers handed out the scales and instructed the students to finish the scales. Third, as for students who could get access to the Internet, voluntary teachers would ask them to accomplish the questionnaires on sojump.com. And students would receive a small gift after completing questionnaires. The data were processed via SPSS version 21.0 and AMOS version 21.0

\section{Measures}

Family cohesion The cohesion subscale of the Chinese version of the second edition of Family Adaptability and Cohesion Scale (Olson et al., 1982; PHILLIPS, WEST, SHEN, \& ZHENG, 1998) was utilized to assess student's family cohesion, which is defined as emotional bonding among family members. The cohesion subscale contains 16 items, responses of which are ranged from 1 (almost never) to 5 (almost always). The Cronbach's alpha of perceived family cohesion is .85 .

School Belonging Students' school identification was assessed by the Questionnaire of School Belonging of Pupils (Guo, 2009), which was specifically designed for Chinese students. There are four subscales and twenty items. School Climate has seven items, which stand for the identification with school climate. Peer relationship involves five items that represent the perception of peer relationships. School Involvement is comprised of five items that reflect the degree of participation in school activities. Academic Engagement indicates the devotion to academic assignments and it is composed of three items. The responses vary from 1 (never) to 5 (always). The Cronbach's alphas of school climate, peer relationship, school involvement, academic engagement and the whole scale are respectively. $79, .77, .75, .58, .88$. 
Sense of Security The Security Questionnaire (Cong, 2004) was intended for evaluating individuals' perception whether they can handle the risks. There are two subscales and eight items for each. Interpersonal security indicates the degree to which individuals feel secure in relationships (e.g., "I feel it difficult to talk with others"). Control security indicates whether individuals have faith in their capacity to take control of their lives (e.g., "I am afraid to decline friends' request"). The responses vary from 1 (always) to 5 (never). The internal consistency of interpersonal security, control security and the whole scale is respectively.72, $.75, .80$.

Achievement goal The Achievement Goal Questionnaire (Yongmei Z, 1999) was applied to appraise the level of achievement goals. The questionnaire has three subscales. Mastery goals consists of five items, they indicate that individuals concentrate on mastering the knowledge and improving competence. Performance-approach goals have five points which mean that students are inclined to hunt for positive judgement of their capacity. Performance-avoidance goals are made up of four items, they show that individuals tend to avoid negative appraisal of their capacity. The scores range from 1 (never) to 5 (always). The Cronbach's alphas of mastery goals, performance-approach goals and performanceavoidance goals are respectively.68, $.67, .80$.

\section{Results}

Descriptive statistics and correlations of family cohesion, school belonging, security and achievement goals are shown in Table 1. Family cohesion is significantly and positively associated with school belonging, interpersonal security, security and mastery goals. School belonging is significantly and positively correlated to interpersonal security, security, mastery goals, performance-approach goals and performance-avoidance goals. Family cohesion doesn't have significant association with control security, performance-approach goals and performance-avoidance goals.

Table 1. Descriptive statistics and correlations of family cohesion, school belonging, security and achievement goals

\begin{tabular}{lllllllll}
\hline & $M \pm S D$ & FC & SB & IS & CS & SE & MG & PAG \\
\hline FC & $2.98 \pm .58$ & & & & & & & \\
SB & $3.85 \pm .63$ & $.35^{* *}$ & & & & & & \\
IS & $3.82 \pm .60$ & $.17^{* *}$ & $.16^{* *}$ & & & & & \\
CS & $3.61 \pm .66$ & .07 & .04 & $.62^{* *}$ & & & & \\
SE & $3.71 \pm .57$ & $.13^{*}$ & $.11^{*}$ & $.89^{* *}$ & $.91^{* *}$ & & & \\
MG & $3.85 \pm .76$ & $.22^{* *}$ & $.49^{* *}$ & .09 & -.08 & -.00 & & \\
PAG & $3.59 \pm .70$ & .08 & $.39^{* *}$ & -.07 & $-.13^{*}$ & $-.12^{*}$ & $.48^{* *}$ & \\
PAVG & $3.36 \pm .87$ & -.05 & $.12^{*}$ & -.13 & $-.18^{*}$ & $-.17^{* *}$ & $.24^{* *}$ & $.46^{* *}$ \\
\hline
\end{tabular}

Note: ( $\left.{ }^{* *} p<.01,{ }^{*} p<.05\right)$ FC, SB, IS, CS, SE, MG, PAG, PAVG are respectively family cohesion, school belonging, interpersonal security, control security, security, mastery goals, performance-approach goals and performance-avoidance goals.

Then we examine the mediating role of security and achievement goals in the relationship of family cohesion and school belonging. Initially, we examine the direct effect of family cohesion on school belonging. The structural model shows an adequate fit (GFI $=.93, \mathrm{IFI}=.91, \mathrm{CFI}=.91)$. The path from family cohesion to school belonging is significant $(\beta=.36, \mathrm{p}<.00)$. So family cohesion can be positively and directly used to predict school belonging.

Then we add interpersonal security, mastery goals and performance-approach goals to the path from family cohesion to school belonging. The SEM analyses indicate an 
acceptable model fit $(\mathrm{GFI}=.93, \mathrm{IFI}=.91, \mathrm{CFI}=.91)$. Family cohesion can predict school belonging $(\beta=.16, \mathrm{p}<.00)$, interpersonal security $(\beta=.17, \mathrm{p}<.00)$ and achievement goals $(\beta=.23, \mathrm{p}<.00)$ positively and significantly. And School belonging is forecasted by interpersonal security $(\beta=.10, \mathrm{p}<.03)$ and achievement goals $(\beta=.69, \mathrm{p}<.00)$. Family cohesion can not only directly predict the school belonging, but predict it via interpersonal security and achievement goals. The $95 \%$ confidence intervals of standardized indirect effects of the path from family cohesion to school belonging vary from .08 to .28 , which are above 0 . Consequently, the mediating effects of interpersonal security and achievement goals are significant.

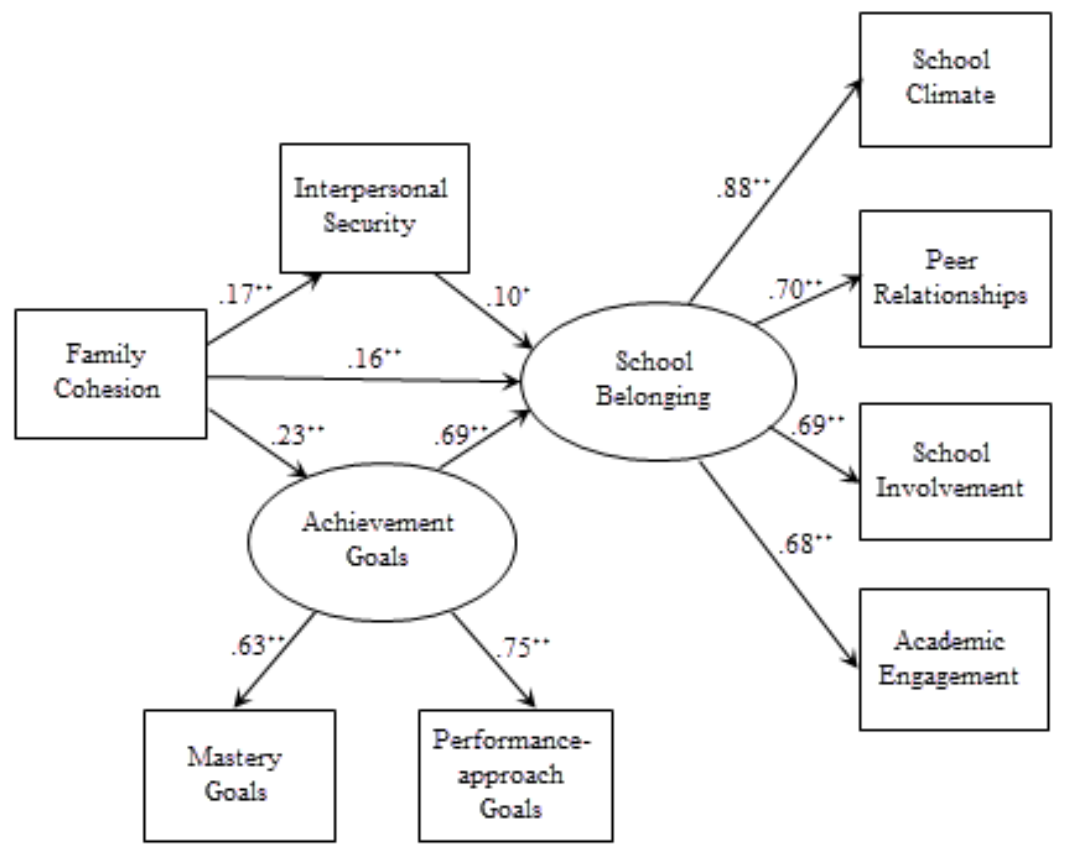

Figure 1. Structural model of the relationships of family cohesion, school belonging, interpersonal security and achievement goals $\left(* * \mathrm{p}<.01,{ }^{*} \mathrm{p}<.05\right)$.

\section{Discussions}

This study examines the relationships of family cohesion and school belonging and proves that interpersonal security and achievement goals have mediating effects in the process. The results show that family cohesion links to school belonging significantly and positively. And family cohesion can predict school belonging directly. In cohesive family, parents will spend more time on educating kids. Therefore, kids will grasp more social skills and be more likely to have positive relationships with others and thus develop stronger school belonging (Maurizi et al., 2013; Sijtsema et al., 2013).

And family cohesion can predict school belonging via interpersonal security. Family cohesion is positively and noticeably associated with interpersonal security. And school belonging can be influenced by family cohesion through the mediating role of interpersonal security. Positive parenting contributes to a sense of security (Bowlby, 2008). Children who have a stronger sense of security are more inclined to feel accepted and supported, which will be conducive to school belonging (Maslow et al., 1945). 
Interpersonal security and control security are assumed to stand for a sense of security (Cong, 2004). However, control security does not link to family cohesion significantly as interpersonal security does. Interpersonal security is considered to be the key factor of a sense of security (Liao et al., 2014). Positive parenting mainly provides children with security in relationships. Students who have a stronger sense of interpersonal security tend to be optimistic and more satisfied with their relationships, contribute to school belonging (Maurizi et al., 2013; Mikulincer et al., 2011). Therefore, interpersonal security alone is more appropriate in representing a sense of security.

Achievement goals mainly consist of mastery goals, performance-approach goals and performance-avoidance goals. Family cohesion correlates positively and significantly to mastery-goals. Family cohesion can predict school belonging via the mediating role of mastery-oriented goals, namely mastery goals and performance-approach goals. In cohesive family, parents will guide children in acquiring social and academic skills and motivate them to do better, which will be conducive to the rise of students' social and academic efficacy (Asghari et al., 2014; Leidy et al., 2012). Students will thus have more faith in themselves and develop mastery-oriented goals, which will contribute to their involvement in academic assignments and school-based activities. According to identify-instruction integration theory (Faircloth \& Hamm, 2005), students are more likely to develop stronger school belonging because of positive feedbacks they receive in school.

We also notice that performance-approach goals and performance-avoidance goals do not associate significantly with family cohesion as mastery goals does. Chinese individuals are prominently influenced by Confucian theories which emphasize the need for harmony in social relationships (PHILLIPS et al., 1998). Therefore, students are not encouraged to show their goal of getting ahead of others, which may impede them from manifesting performance-approach goals. Besides, students from cohesive family develop higher selfefficacy and have more faith in their competence, which will prevent them from falling into performance-avoidance goals (Leidy et al., 2012). And the detrimental effects of achievement goals are only showed in performance-avoidance goals (Elliot \& Harackiewicz, 1996). Consequently, it still includes performance-approach goals in achievement goals. In this case, achievement goals are equal to mastery-oriented goals (Dweck, 1986).

When referring to the improvement of school belonging, most researchers start from school climate, including peers, faculties and extracurricular activities (Matthews, Banerjee, \& Lauermann, 2014; Walton, Cohen, Cwir, \& Spencer, 2012). Few researchers probe into the cooperation of family and school (Cheung, 2011). This study indicates that family cohesion can predict school belonging positively and directly. Interpersonal security and achievement goals play a mediating role in the process. Parents can make more family communication with kids, respond to children request swiftly and guide them in social interactions and academic assignments. In the process, students will develop a sense of interpersonal security and have more faith in their competence, which may be beneficial to their relationships with peers and teachers, involvement in extracurricular activities and engagement in academic assignments. Students may thus have a stronger sense of school belonging.

\section{References}

1. Asghari, F., Saadat, S., Atefi Karajvandani, S., \& Janalizadeh Kokaneh, S. 2014. The Relationship between Academic Self-Efficacy and Psychological Well-Being, Family Cohesion, and Spiritual Health among Students of Kharazmi University. Iranian Journal of Medical Education, 14(7): 581-593. 
2. Bowlby, J. 1982. Attachment and loss: retrospect and prospect. American Journal of Orthopsychiatry, 52(4): 664.

3. Bowlby, J. 2008. A secure base: Parent-child attachment and healthy human development: Basic Books.

4. Cheung, C.-k. 2011. Children's Sense of Belonging and Parental Social Capital Derived from School. Journal of Genetic Psychology, 172(2): 199-208. doi: 10.1080/00221325.2010.520362

5. Cong, Z., \& An, L. J. 2004. Developing of Security Questionnaire and its Reliability and Validity. Chinese Mental Health Journal, 18(2): 97-99.

6. Cook, J. E., Purdie-Vaughns, V., Garcia, J., \& Cohen, G. L. 2012. Chronic threat and contingent belonging: Protective benefits of values affirmation on identity development. J Pers Soc Psychol, 102(3): 479-496. doi: 10.1037/a0026312

7. Crespo, C., Kielpikowski, M., Pryor, J., \& Jose, P. E. 2011. Family rituals in New Zealand families: links to family cohesion and adolescents' well-being. Journal of Family Psychology, 25(2): 184.

8. Dweck, C. S. 1986. Motivational processes affecting learning. American psychologist, 41(10): 1040.

9. Dweck, C. S., \& Bempechat, J. 1983. Children's theories of intelligence: Consequences for learning. Learning and motivation in the classroom, 239-256.

10. Elliot, A. J., \& Harackiewicz, J. M. 1996. Approach and Avoidance Achievement Goals and Intrinsic Motivation: A Mediational Analysis. Journal of Personality \& Social Psychology, 70(3): 461-475.

11. Faircloth, B. S., \& Hamm, J. V. 2005. Sense of belonging among high school students representing 4 ethnic groups. Journal of Youth and Adolescence, 34(4): 293-309.

12. Goodenow, C. 1993. The psychological sense of school membership among adolescents: Scale development and educational correlates. Psychology in the Schools, 30(1): 79-90.

13. Guo, G. 2009. The Relationship between the Family Relationship of Pupils and the School Belonging of Pupils (Master), Sichuan Normal University, Chengdu, Sichuan, China.

14. Hagborg, W. J. 1994. An exploration of school membership among middle-and highschool students. Journal of Psycho educational Assessment, 12(4): 312-323.

15. Hamama, L., \& Arazi, Y. 2012. Aggressive behaviour in at-risk children: contribution of subjective well-being and family cohesion. Child \& Family Social Work, 17(3): 284295.

16. Leidy, M. S., Guerra, N. G., \& Toro, R. I. 2012. Positive parenting, family cohesion, and child social competence among immigrant Latino families. Journal of Latina/o Psychology, 1(S): 3-13. doi: 10.1037/2168-1678.1.S.3

17. Liao, C., Hu, Y., \& Zhang, J. 2014. Measuring the sense of security of children left behind in China. Social Behavior and Personality: an international journal, 42(10): 1585-1601.

18. Lindahl, K. M., \& Malik, N. M. 2011. Marital conflict typology and children's appraisals: the moderating role of family cohesion. Journal of Family Psychology, 25(2): 194.

19. Maslow, A. H., Hirsh, E., Stein, M., \& Honigmann, I. 1945. A clinically derived test for measuring psychological security-insecurity. The Journal of general psychology, 33(1): 21-41.

20. Matthews, J. S., Banerjee, M., \& Lauermann, F. 2014. Academic Identity Formation and Motivation among Ethnic Minority Adolescents: The Role of the "Self" Between Internal and External Perceptions of Identity. Child Development, 85(6): 2355-2373. doi: $10.1111 /$ cdev. 12318 
21. Maurizi, L. K., Ceballo, R., Epstein-Ngo, Q., \& Cortina, K. S. 2013. Does neighborhood belonging matter? Examining school and neighborhood belonging as protective factors for Latino adolescents. American Journal of Orthopsychiatry, 83(2-3): 323-334. doi: 10.1111/ajop.12017

22. Merkaš, M., \& Brajša-Žganec, A. 2011. Children with different levels of hope: are there differences in their self-esteem, life satisfaction, social support, and family cohesion? Child Indicators Research, 4(3): 499-514.

23. Mikulincer, M., Shaver, P. R., \& Rom, E. 2011. The effects of implicit and explicit security priming on creative problem solving. Cognition and Emotion, 25(3): 519-531.

24. Moreira, H., Frontini, R., Bullinger, M., \& Canavarro, M. C. 2014. Family Cohesion and Health-Related Quality of Life of Children with Type 1 Diabetes: The Mediating Role of Parental Adjustment. Journal of Child and Family Studies, 23(2): 347-359.

25. Olson, D. H., McCubbin, H. I., Barnes, H., Larsen, A., Muxen, M., \& Wilson, M. 1982. Family inventories: Inventories used in a national survey of families across the family life cycle: University of Minnesota St. Paul, MN.

26. Phillips, M. R., West, C. L., Shen, Q., \& Zheng, Y. 1998. Comparison of schizophrenic patients' families and normal families in China, using Chinese versions of FACES-II and the family environment scales. Family Process, 37(1): 95-106.

27. Sijtsema, J. J., Nederhof, E., Veenstra, R., Ormel, J., Oldehinkel, A. J., \& Ellis, B. J. 2013. Effects of family cohesion and heart rate reactivity on aggres-sive/rule-breaking behavior and prosocial behavior in adolescence: The Tracking Adolescents' Individual Lives Survey study. Development and psychopathology, 25(03): 699-712.

28. Tolan, P. H., Gorman-Smith, D., Huesmann, L. R., \& Zelli, A. 1997. Assessment of family relationship characteristics: a measure to explain risk for antisocial behavior and depression among urban youth. Psychological Assessment, 9(3): 212.

29. Walton, G. M., Cohen, G. L., Cwir, D., \& Spencer, S. J. 2012. Mere belonging: The power of social connections. J Pers Soc Psychol, 102(3): 513-532.

30. Wehlage, G. G. 1989. Dropping out: can schools be expected to prevent it: Dropouts from school: issues, dilemmas, and solutions. Albany, NY: State University of New York Press.

31. Yongmei Z, P. F. C. G. 1999. Experiments about the Achievement Goal Theory and its Pattern of Motivation Psychological Science, 22(5): 463-464.

32. Yoo, Y., Adamsons, K., Robinson, J., \& Sabatelli, R. 2015. Longitudinal Influence of Paternal Distress on Children's Representations of Fathers, Family Cohesion, and Family Conflict. Journal of Child \& Family Studies, 24(3): 591-607. doi: 10.1007/s10826013-9870-7

33. Yuhui, Q., \& Xiang, W. 2015. Review of School Belonging. Paper presented at the 2015 International Conference on Social Science and Technology Education. 